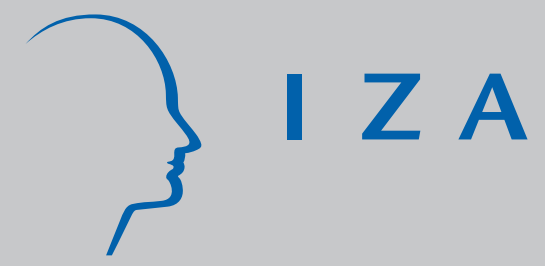

IZA DP No. 9319

Be a Good Samaritan to a Good Samaritan: Field Evidence of Interdependent Other-Regarding Preferences in China

Simon Chang

Thomas S. Dee

Chun Wing Tse

Li Yu

August 2015 


\title{
Be a Good Samaritan to a Good Samaritan: Field Evidence of Interdependent Other-Regarding Preferences in China
}

\author{
Simon Chang \\ University of Western Australia and IZA \\ Thomas S. Dee \\ Stanford University \\ Chun Wing Tse \\ Central University of Finance and Economics \\ Li Yu \\ Central University of Finance and Economics
}

Discussion Paper No. 9319

August 2015

IZA

P.O. Box 7240

53072 Bonn

Germany

Phone: +49-228-3894-0

Fax: +49-228-3894-180

E-mail: iza@iza.org

\begin{abstract}
Any opinions expressed here are those of the author(s) and not those of IZA. Research published in this series may include views on policy, but the institute itself takes no institutional policy positions. The IZA research network is committed to the IZA Guiding Principles of Research Integrity.

The Institute for the Study of Labor (IZA) in Bonn is a local and virtual international research center and a place of communication between science, politics and business. IZA is an independent nonprofit organization supported by Deutsche Post Foundation. The center is associated with the University of Bonn and offers a stimulating research environment through its international network, workshops and conferences, data service, project support, research visits and doctoral program. IZA engages in (i) original and internationally competitive research in all fields of labor economics, (ii) development of policy concepts, and (iii) dissemination of research results and concepts to the interested public.
\end{abstract}

IZA Discussion Papers often represent preliminary work and are circulated to encourage discussion. Citation of such a paper should account for its provisional character. A revised version may be available directly from the author. 
IZA Discussion Paper No. 9319

August 2015

\section{ABSTRACT}

\section{Be a Good Samaritan to a Good Samaritan: Field Evidence of Interdependent Other-Regarding Preferences in China}

We conducted large-scale lost letter experiments in Beijing, a megacity with more than 21 million residents, to test if the observed altruistic attribute of the letter recipient would induce more passersby to return the lost letters. The treatment letters were addressed to a nationally renowned charitable organization in China, while the control letters were intended to an invented individual. A total of 832 ready-to-be-posted letters were distributed in 208 communities across eight districts in the city. The overall return rate was only about $13 \%$. Yet, the return rate of the treatment letters (17\%) was nearly twice as high as that of the control letters (9\%). The finding adds large-scale field experiment evidence in support of the interdependent other-regarding preferences theory. In addition, we also found that the lost letters were more likely to be returned if they were dropped in communities with a relatively higher income or a postal box located closer.

JEL Classification: C93, D03

Keywords: $\quad$ other-regarding preferences, lost letter technique, altruism, China

Corresponding author:

Simon Chang

University of Western Australia

35 Stirling Highway

Crawley, WA 6009

Australia

E-mail: simon.chang@uwa.edu.au 
"How selfish soever man may be supposed, there are evidently some principles in his nature, which interest him in the fortune of others, and render their happiness necessary to him, though he derives nothing from it except the pleasure of seeing it."---Adam Smith (1759), the Theory of Moral Sentiments

\section{Introduction}

The self-interest hypothesis of the homo economicus remains a deeply ingrained assumption in modern economics. Yet, since Adam Smith, many prominent economists have pointed out that people are often concerned about the well-being of others and such other-regarding preferences may have important economic consequences (Smith 1759; Becker 1974; Arrow 1981; Samuelson 1993; Simon 1993; Sen 1995). ${ }^{1}$ Meanwhile, behavioral economists have gathered, mostly via laboratory experiments in the past few decades, a large body of evidence against the self-interest hypothesis. In response, a variety of other-regarding preferences theories were proposed to explain the experimental findings (Fehr and Schmidt 2006; Cooper and Kagel 2013).

A strand of the theories is called the interdependent other-regarding preferences theory, which stresses that an individual's other-regarding preferences toward a subject depend on the subject's characteristics and personalities (Levine 1998; Gul and Pesendorfer 2006; Rotemberg 2008). In particular, this theory predicts that a person is more willing to help an altruistic subject than a non-altruistic subject, because her satisfaction positively depends on the subject's altruistic preference (see section 2 for

\footnotetext{
${ }^{1}$ In general, other-regarding preferences refer to that the well-being of others is a determinant of one's utility. However, the effect of others' well-being on one's utility can be either positive or negative. If the effect is positive, one is considered to have altruistic preferences. On the contrary, if the effect is negative, one is then viewed as having spiteful preferences.
} 
more discussions on the theory). In this paper, we conducted large-scale field experiments to test this theoretical prediction.

In particular, we adopted a tool of social research called the lost letter technique (LLT), which was originally devised by Stanley Milgram, an American social psychologist, in the 1960s (Milgram et al. 1965). The LLT intentionally leaves ready-tobe-mailed letters on the ground or any visible place for people who pass by to pick up and drop into a postal box. The return rate of the lost letters is then used to measure the level of other-regarding preferences, or altruistic preferences in this paper, of the passersby.

We carried out the lost letter experiments in Beijing, which is one of the most populous megacities in the world with more than 21 million residents. A total of 832 letters were distributed in 208 communities across eight districts in the city. ${ }^{2}$ Half of the letters were addressed to a nationally renowned charitable organization in China to serve as the treatment letters. The other half was intended to an invented individual with a gender-neutral name as the control letters. Such design is to test if the altruistic nature of the charitable organization, which the invented individual lacks, would induce more passersby to return the lost letters. To the best of our knowledge, this is the first largescale field experiment carried out to test the theory of interdependent other-regarding preferences.

It is worth noting that in contrast to most laboratory experiments, the LLT does not involve any physical encounter between the passersby and the letter recipients. It is

\footnotetext{
2 The eight districts include all six districts in central Beijing and two in the suburban area. According to the Bureau of Statistics in Beijing, the population of the eight districts in 2013 amounts to 15.7 million or $74 \%$ of the total population in Beijing. In our study, the number of the residents living in the 208 communities is estimated to be at least 40,000.
} 
also unlikely that the actions of the passersby were triggered by a reciprocal motive, as they were unlikely to foresee any interaction with the letter recipients in the future.

Our main experiment result shows that the overall return rate was only 13\%. Yet, the return rate of the treatment letters, $16.83 \%$, was almost twice as high as that of the control letters, 9.13\%, suggesting that the passersby did exert more altruistic efforts when the letter recipient appeared to be an altruistic subject. In other words, their otherregarding preferences do depend on the characteristics of the recipients. In addition, we also found that the return rate was positively associated with the community's income but negatively related to the distance to the postal box. The timing of letter dropping also matters as we found that the return rate increased steadily for letters dropped between 7$10 \mathrm{AM}$ and then suddenly plummeted after 10AM. This finding is likely to be correlated with the changing number and composition of the passersby across hours.

Admittedly, there are other differences between the charitable organization and the invented individual. ${ }^{3}$ For example, the former is an organization, while the latter is an individual. However, previous studies do not suggest that the return rate would necessarily be different between an organization and an individual (Milgram et al. 1965; Farrington and Knight 1980). It mostly depends on the nature of the organization. Another difference is that the former is reputable, while the latter is simply an unknown individual. Yet, the charitable organization in this study has built its good reputation by

\footnotetext{
${ }^{3}$ It would be ideal to compare the charitable organization with a "neutral" organization that has no feature. However, such neutral organization simply does not exist, since all organizations are founded for specific reasons, e.g. for profit or not for profit, that define the nature of each organization.
} 
helping others. In this sense, it is still the altruistic nature of the charity that raises the return rate. ${ }^{4}$

Restricted by the experimental design, we were unable to directly observe the characteristics of the passersby as well as the process that mediated the return of the letters. Although we collected information on the income of the community residents via pre-experiment survey, we could not rule out the possibility that non-residents could also come across the lost letters, which at least clouds the effect of the income on the return rate. Despite these limitations, our paper contributes to the literature by adding the first large-scale field experiment evidence in support of the interdependent other-regarding preferences theory.

The rest of this paper is organized as follows. The second section reviews the related literature. The third section delineates the experiment design in details. The fourth section reports the experiment results. The fifth section discusses the motives and alternative explanations. We then conclude in the last section.

\section{Other-regarding Preferences: Theories and Experimental Evidence}

\subsection{Theories of Other-regarding Preferences}

The conventional way of introducing other-regarding preferences into economic models under the rational choices framework is to directly add the well-being of others into an individual's utility function. For instance, Becker (1976) used the following implicit utility function.

$$
u_{i}=u\left(x_{i}, x_{j}\right), \quad i \neq j
$$

\footnotetext{
${ }^{4}$ On the contrary, one can imagine that an organization with a bad reputation would probably have a low return rate.
} 
where $u_{i}$ is person $i$ 's utility. $x_{i}$ is $i$ 's own measure of well-being, e.g. consumption, while $x_{j}$ is person $j$ 's measure of well-being. Person $i$ is considered as being altruistic if her marginal utility of $x_{j}$ is strictly positive, i.e. if her utility increases with the well-being of person $j$. On the contrary, she is spiteful or envious if her marginal utility of $x_{j}$ is strictly negative, meaning her utility decreases with the well-being of person $j$. Equation (1) can be easily extended to include $n$ individuals.

One example of linear utility is $u_{i}=x_{i}+a_{i} x_{j}$, where $a_{i}$ is the coefficient of person $i$ 's other-regarding preference. Person $i$ is altruistic if $a_{i}>0$ and vice versa. In this case, the other-regarding preference coefficient, $a_{i}$, is a constant and does not depend on person $j$ 's characteristics.

Variants of other-regarding preferences models were mostly developed in the last two decades such as the outcome-based social preferences models (Fehr and Schmidt 1999; Bolton and Ockenfels 2000), the interdependent preferences models (IPMs) (Levine 1998; Gul and Pesendorfer 2006; Rotemberg 2008), the intention-based reciprocity models (Rabin 1993; Dufwenberg and Kirchsteiger 2004). The outcomebased models assume that a person's utility is a function of the resources allocated to her and others. The interdependent preferences models (IPMs) allow an individual's otherregarding preferences to depend on the "types" of other people. Intention-based models assume that an individual cares about other people's intentions and motives. In lieu of providing a comprehensive review of the theories, this section only briefly demonstrates one example of the IPMs, which our experiment aimed to test. ${ }^{5}$

\footnotetext{
${ }^{5}$ Read Fehr and Schmidt (2006) for a recent review of the theories.
} 
In the simplest case of two players, a modified model based on Levine (1998) is illustrated as follows. ${ }^{6}$

$u_{i}=x_{i}+\frac{a_{i}+\lambda a_{j}}{1+\lambda} x_{j}, i \neq j, 0 \leq \lambda \leq 1,-1<a<1$,

where $u_{i}, x_{i}, x_{j}$ and $a_{i}$ are defined as the same as above, while $a_{j}$ is the coefficient of person $j$ 's other-regarding preference.

As before, person $i$ is considered as being altruistic if $a_{i}>0$. Yet, her marginal utility derived from $j$ 's well-being depends on whether $j$ is altruistic, i.e. $a_{j}>0$, indifferent, i.e. $a_{j}=0$, or spiteful, i.e. $a_{j}<0$, as well as the value of $\lambda$. $^{7}$ Let $\lambda$ be positive, then person $i$ 's marginal utility of $x_{j}$ is higher if $j$ is altruistic and lower vice versa. This implies that an altruistic person will be more willing to help improving the well-being of an altruistic subject than an indifferent or spiteful subject. Even for a spiteful person, his spitefulness will be offset by the altruism of the other player and he will even help an altruistic player if $a_{j}>-a_{i} / \lambda$.

Other variants of the IPMs also feature the interdependence of other-regarding preferences in different ways. One of the important theoretical predictions from the IPMs is that an individual would become more altruistic if the opponent is also altruistic, which we tested in this study.

\subsection{Experimental Evidence}

Since the early 1980s, behavioral economists have been collecting a large body of evidence against the self-interest hypothesis via various laboratory games such as the ultimatum game, the dictator game, the power to take game, the third party punishment

\footnotetext{
${ }^{6}$ In the original model, Levine allows $n$ players and the second component on the right-hand-side in equation (2) sums over all players $j \neq i$.

${ }^{7}$ Note that when $\lambda$ is zero, the model reduces to a pure altruism model as the previous linear example.
} 
game, the gift exchange game, the trust game etc. (Roth, Malouf and Murningham 1981;

Güth, Schmittberger and Schwarze 1982; Fehr, Kirchsteiger and Riedl 1993; Forsythe et al. 1994; Berg, Dickhaut and McCabe 1995; Bosman and Winden 2002; Fehr and Fischbacher 2004). In all these games, one player has a strictly dominant strategy if he is purely selfish. Yet, a robust result from these experiments is that people often deviate away from the selfish strategy. ${ }^{8}$ Therefore, the bulk of experimental evidence inspired alternative explanations and provoked the burgeoning of the aforementioned otherregarding preferences theories, including the IPMs.

While different other-regarding preferences theories attempted to capture different motives and aspects of other-regarding behavior in game experiments, it has been shown that with appropriate parameterizations, all of them can possess an equilibrium that is consistent with the extant experimental results. It is probably because of this, there was almost no experimental study that was able to test a specific theory by ruling out alternative explanations.

As a welcomed exception, Halevy and Peters (2013) was probably the first and only paper that aimed to experimentally separate these theories. They modified the classic dictator game by imposing a lower limit on the offer that the proposer could make. They found that the lower limit on the offer decreased the proposer's offer and increased the responder's acceptance rate, results that are consistent with the interdependent

\footnotetext{
${ }^{8}$ Take the ultimatum game for instance, player A proposes a division of a fixed sum of money with player $\mathrm{B}$, who then can either accept or reject the proposal. In case of rejection, both players receive nothing. In case of acceptance, the proposal is implemented. If both players are rational and selfish, the subgame perfect equilibrium prescribes that player B accepts any positive amount of money and player A gives player B the smallest amount to B and keeps the rest to himself. However, hundreds of experiments show that a vast majority of the player A offers 40 to 50 percent of the fixed sum. In addition, about $40 \%$ to $60 \%$ of the offers lower than $20 \%$ of the fixed sum are rejected. See Fehr and Schmidt (2006) for a review.
} 
preference models but inconsistent with the outcome-based models and the intentionbased models.

\section{Experiment Design}

\subsection{The Lost Letter Technique}

In their famous experiment in 1965, Stanley Milgram and his associates distributed 100 ready-to-be-mailed envelopes addressed to each of the following four subjects: 1) Friends of the Communist Party, 2) Friends of the Nazi Party, 3) Medical Research Associates and 4) Mr. Walter Carnap in the city of New Haven, Connecticut. They used the return rates as a behavioral measure of attitudes for that they can be influenced by the intended subjects written on the envelopes. They coined the term the lost letter technique (LLT) for such experimental design.

The overall return rate in their study was $48 \%$. However, the return rate was much higher for the Medical Research Associates (72\%) and Mr. Walter Carnap (71\%) than for the two extremist political groups, the Friends of the Communist Party (25\%) and the Friends of the Nazi Party (25\%). The results suggested that when a person came across a lost letter, the likelihood that she would return it depends on her attitude on the intended subject. In particular, a low return rate would indicate a negative attitude and vice versa. It is worth noting that the Medical Research Associates as an organization and Mr. Walter Carnap as an individual had almost the same return rate while the other two organizations had much lower return rates. This suggests that compared to an individual, the return rate for an organization could be either higher or lower, depending on the characteristics of the organization of interest. 
Since their study, the LLT has been widely used in social sciences research. As being pointed out in Milgram et al. (1965), the advantages of the LLT include: 1) the passerby rarely realizes that she is participating in an experiment; 2) an ordinary action is used as a behavioral measure; 3) the returned letters can be easily gathered in a post office box. Yet, the major shortcoming of the LLT is that experimenters lack control of the process that mediates the return of the letters.

In our lost letter experiments, returning a letter requires three actions of the passerby: 1) spot the letter; 2) pick it up and 3) drop it in a postal box. Most likely, a person's other-regarding preferences begin to exert an effect after she spots the letter. When she decides to return the letter, she has to incur a cost of finding a postal box and walking toward it. Therefore, the cost of returning a letter mainly depends on the distance to the postal box.

\subsection{Treatment and Control Letters}

In our experiments, half of the letters were assigned to the following recipient and address, originally written in Chinese, as the treatment letters.

China Youth Development Foundation Hope Project

P.O. Box 100081-XXX

The other half was assigned to the following recipient and address as the control letters.

Yang Yang

P.O. Box 100081-XXX

The China Youth Development Foundation (CYDF) is a nationally renowned charitable organization in China and famous for its Hope Project initiated in 1989 that 
aims to help poor students. To present, the Hope Project has funded more than 4.9 million poor students and built 18,335 primary schools and 20,640 libraries across China. On the contrary, Yang Yang is an invented person with a gender-neutral Chinese name and no known altruistic attribute.

A one-page thank you letter was included in every envelope intended to CYDF. Likewise, a one-page commercial advertisement was inserted into the envelopes for Yang Yang. The purpose of including the fabricated letters was to make them look like real lost letters. All envelopes were tightly sealed so that we could easily detect if a returned letter was ever opened. To make the letters ready to be posted, we stamped them all. For tracking purpose, we marked a unique code on the back of and inside each envelope to indicate the type of letter, date and community.

In each community, two treatment and two control letters were dropped on the ground inside the community near the entrance in four consecutive days. The purpose of placing the letters inside the community was to make the letters more likely to be seen and picked up by the community residents instead of strangers who just walked by. The dropping sequence of the letters was randomized based on the postal box location, district and the self-reported average monthly income of the residents.

\subsection{Recruiting and Training of Volunteers}

We recruited 15, 14, and 24 volunteers in the first, second and third round of experiment respectively. All volunteers were master students majoring in Labor Economics at the Central University of Finance and Economics located in the Haidian district in Beijing. Prior to each experiment, volunteers were required to attend two training sessions. In the first session, students were exposed to the details of the experiment design and assigned to search for a number of residential communities with a 
postal box either inside or nearby. They were also trained to conduct a pre-experiment survey to collect community information such as community name, address and district, postal box location relative to the entrance, and average monthly income of the residents. Information about average monthly income was self-reported by local residents through interview. In the second session, volunteers prepared the stamped letters and received training on dropping techniques such as where to drop the letters and how to avoid suspicions of the residents. More importantly, they were told to record the dropping time and date as well as various weather indicators for each letter they dropped.

\subsection{Summary of the Three Experiments}

As a pilot study, the first experiment was conducted during January $1^{\text {st }}-4^{\text {th }}$ in 2012 in 48 communities in Beijing (Table 1). The second round was carried out during November $18^{\text {th }}-21^{\text {st }}$ in 2013 in 60 communities. At last, the third round, also the largest one, took place during March $26^{\text {th }}-29^{\text {th }}$ in 2014 in 100 communities. The dropping days covered all seven days in a week. As for dropping time, most of the letters were dropped between 7AM and 10AM with only 30 letters being dropped after 10AM in the pilot experiment.

Four letters—-two treatment and two control—were dropped in each community in a randomized sequence. The randomization was based on the self-reported average monthly income of the community residents, postal box location and district. A total of 832 letters were dropped in the three rounds of experiments, including 192, 240 and 400 in the first, second and third wave respectively (Table 2). Half of the letters were assigned as the treatment letters and the other half as the control letters. 
The 208 communities were located across eight districts in Beijing, including six in central Beijing and two in the suburban area (Figure 1). It is worth noting that the number of communities in each district does not reflect its population size. The selection of the communities was primarily based on whether a community has a postal box inside or nearby and the transportation cost. Since our volunteers were based in the Haidian district, it is not surprising that a disproportionately large cluster of communities were located there.

Column (5) in Table 3 reports the percentage of communities in each district that had a self-reported average income of the residents above 5,000 RMB per month. In our sample, the three richest districts are Haidian, Dongchen and Xicheng district in central Beijing, while the poorest two are the suburban districts of Tongzhou and Changping. To check if this income ranking of our sample is consistent with the population, we acquired the data on per capita disposable income of residents with urban Hukou, i.e. household registration, in 2013 from the Bureau of Statistics of the Beijing City. As shown in column (7), the disposable income ranking is similar to the ranking in column (6).

Since the three experiments were conducted in different seasons, there was a large variation in the temperature (Table 4). The first two waves were carried out in winter with the highest temperature ranging between 1 to 3 degrees Celsius. The third wave took place in the early spring with the highest temperature between 21 to 22 degrees Celsius. There was also some variation in the wind speed from day to day, but the wind was generally rather mild. The sky of the day was either sunny or cloudy.

\section{Experimental Results}

\subsection{Main Results}


Of the 832 letters, only about 13\% of them were eventually returned (Panel A in Table 5). Despite the low overall return rate, the return rate of the treatment letters was almost twice as high as that of the control letters. More specifically, the return rate was $16.83 \%$ for the treatment letters, while it was only $9.13 \%$ for the control letters. The difference was as large as 7.7 percentage points and statistically significant. The pattern that treatment letters had a higher return rate that control letters was consistently observed across all three waves of experiments, although the difference in return rates also varied across experiments (Panel B in Table 5).

\subsection{Return Rates by Subgroups}

If we break down the return rates by subgroups, some interesting variations are revealed. The upper-left panel in Figure 2 shows that the return rate was the highest for the highest income group, which is consistent with the findings by Lowe and Ritchey (1973) and Brown and Reed (1982). The upper-right panel shows that the return rate decreased with the distance to the postal box. There are two possible explanations for this observation. One is that the distance to the postal box is a major cost of the altruistic act. The longer the distance, the higher the cost and the less likely an individual would like to help. The other explanation could be that the farther away the postal box, the more difficult for an individual to find it, thus lowering the return rate.

The lower-left panel reveals a variation in return rate across the seven days in a week. The return rate appeared to be the highest on Friday and Saturday and the lowest on Monday. As for time in the lower-right panel, the return rate increased steadily over time until 10AM when there was a significant drop. The variation in return rate over day 
and time may have been caused by the variation in the number or the composition of people who walked by the lost letters.

Figure 2 displays the variation by weather indicators. The upper-left panel shows that the return rates in cloudy days were higher than in sunny days. To the contrary, the wind speed did not seem to cause much variation in the upper-right panel. In the bottom two panels, the return rate was general higher when it was warmer. This is likely because more people would walk by the letters when it is warm.

\subsection{Regression Results}

Previous analysis is based on unconditional return rates. To estimate more precise ceteris paribus partial effects of the variables, we regress a dummy variable indicating if a letter was returned on a set of explanatory variables. The key explanatory variable is a treatment dummy indicating if a letter was a treatment letter. Other control variables include income, postal box location, dropping time and day, a set of weather indicators and a full set of wave and district dummy variables. The regression results are reported in Table 6. The differences between column (1), (2) and (3) are the inclusion of a dummy variable indicating the self-reported average monthly income of the residents was above 5,000 RMB as well as an interaction term of the income dummy and the treatment dummy.

In both column (1) and (2), the treatment effect is 7.8 percentage points and statistically significant, suggesting that the return rate of the treatment letters is higher than that of the control letters by 7.8 percentage points, which is almost identical to the unconditional estimate in Panel A in Table 5. 
The estimate of the high income dummy in column (2) suggests that the return rate of the high income group is 4.4 percentage points higher than that of lower income group ( $<5,000 \mathrm{RMB})$. Yet, it is only marginally significant at 10\%. In column (3), we further added an interaction of the treatment dummy and the high income dummy to see if the treatment effect varies by income. The interaction term suggests that the return rate of the treatment letters dropped in higher income communities is 3.6 percentage points higher than their counterparts in lower income communities. However, the estimate is not statistically significant.

The estimates of the postal box location dummies in all three columns are consistent with our previous observation in Figure 1. Compared with the case where the postal was located inside the community, the return rate decreases with the distance to the postal box. As for the dropping time, the letters dropped during 9-10AM has the highest return rate. Relative to those letters dropped during 7-8AM, the return rate of 9-10AM is 13.2 percentage points higher in column (1). A surprising result is that the return rate of 10AM and afterwards is also higher than 7-8AM, although it is not statistically significant. The remaining estimates suggest that the return rate is higher in week days, cloudy days, with higher temperature and lower wind speed. However, none of these estimates is statistically significant.

\section{Discussions on Motives and Alternative Explanations}

There could be multiple motives underpinning the returning of the lost letters. For both the treatment and control letters, the passerby's act of returning the lost letter could be motivated by pure altruism, a desire to become praiseworthy or to avoid scorn of others. Pure altruism was unconditional and did not take others’ attitudes into consideration, whereas the latter two motives were superimposed upon a person by social 
pressures. Unfortunately, the LLT does not allow us to disentangle the mixture of motives.

Instead, our focus was the relative return rates between the treatment and control letters. From the perspective of pure altruism, returning the lost letter for the charitable organization could imply helping not only the organization but also the tens of thousands of children who received help from the organization. In contrast, returning the lost letter for the invented individual was just helping one person. Therefore, one would derive a higher level of satisfaction by returning a treatment letter than a control letter. On the other hand, if one was mainly motivated by social pressures, the higher return rate of the treatment letters could imply that the social norms or culture prescribed a greater "importance" to the charitable organization over the individual.

Admittedly, there were other differences between the charitable organization and the invented individual. First, the former was an organization, while the latter was an individual. Yet, prior studies do not suggest such distinction alone would necessarily lead to significant differences in the return rate. Based on the results in Milgram et al. (1965), the return rate of an organization can be either higher or lower than that of an individual, depending on the characteristics of the organization. As another example, instead of measuring the return rate of the lost letters, Farrington and Knight (1980) studied whether the passersby would "steal" unsealed lost letters that contained a small amount of cash. In their study, the "non-return" rate of letters intended for an individual was not significantly different from that of the letters for an association, either. Moreover, organizations are always established for reasons that define their nature. It would seem impossible to imagine a "neutral” organization without any attribute. 
Another noticeable difference is that the CYDF is nationally renowned, while Yang Yang is an invented individual with no known reputation. It is possible that the passersby may have found the CYDF trustworthy due to its national reputation and thus be more willing to help it. Such trustworthiness may make a person feel the CYDF more worth of her help, although this conjecture requires further examinations. However, it is difficult to disentangle the trustworthiness from the altruistic nature of the CYDF. After all, it is the charity nature that makes the CYDF renowned and trustworthy.

At last, some passersby may consider letters addressed to the CYDF are more important-for example, they may conjecture that the letters contain monetary donations to the charity, so they are more likely to return the letters. While this may be possible for some people, it is also likely that other people with the same conjecture would respond differently by stealing the donations, in lieu of returning the letters.

\section{Concluding Remarks}

As Fehr and Fischbacher (2003) pointed out "some of the most fundamental questions concerning our evolutionary origins, our social relations, and the organization of society are centered around issues of altruism and selfishness. ... However, there is much individual heterogeneity and the interaction between altruists and selfish individuals is vital to human cooperation.” This paper sheds some light on the individual heterogeneity and the interaction between altruists and egoists. Our lost letter experiment results show that a person becomes more altruistic and willing to help if she knows ex ante the beneficiary of her help is an altruistic subject.

Our evidence was collected in Beijing, a megacity in the world's largest developing country. The external validity of our results depends on contextual factors such as culture, demographic environment, and technology, which may have to some 
extent weighed in the results. How general our findings can be applied to other settings require more research in other cultural and environmental settings in the future. 


\section{REFERENCES}

Arrow, K., (1981). “Optimal and Voluntary Income Redistribution,” in Rosenfield, S.(Ed.), Economic Welfare and the Economics of Soviet Socialism: Essays in Honor of Abram Bergson, Cambridge: Cambridge University Press.

Becker, G., (1974). “A Theory of Social Interactions,” Journal of Political Economics, 82 (6), pages 1063-1093.

(1976). “Altruism, Egoism, and Genetic Fitness: Economics and Sociobiology,” Journal of Economic Literature, 14(3), pages 817-826.

Berg, J., J. Dickhaut, and K. McCabe, (1995). “Trust, Reciprocity and Social History,” Games and Economic Behavior, 10, pages 122-142.

Bolton, G., and A. Ockenfels, (2000). "A Theory of Equity, Reciprocity and Competition,” American Economic Review, 100, pages 166-193.

Bosman, R., and F. van Winden, (2002). "Emotional Hazard in a Power-to-TakeExperiment,” Economic Journal, 112, pages 147-169.

Brown, C., and M. Reed, (1982). "Race, Cost, and Car-Status: Interacting Variables Using the Lost-letter Technique,” Psychological Reports, 51, pages 303-308.

Cooper, D., and J. Kagel, (2013). “Other-Regarding Preferences: A Selective Survey of Experimental Results,” to appear in Kangel, J., and Roth, A. (Eds), Handbook of Experimental Economics, Volume (2), Princeton University Press.

Dufwenberg, M., and G. Kirchsteiger, (2004). "A Theory of Sequential Reciprocity,” Game and Economic Behavior, 47, pages 268-298.

Farrington, D., and B. Knight, (1980). "Stealing from a "Lost” Letter Effects of Victim Characteristics,” Criminal Justice and Behavior, 7(4), page 423-436. 
Fehr, E., and U. Fischbacher, (2003). “The Nature of Human Altruism,” Nature, 425, pages 785-791. (2004). “Third Party Punishment and Social Norms,” Evolution and Human Behavior, 25, pages 63-87.

Fehr, E., G. Kirchsteiger, and A. Riedl, (1993). "Does Fairness Prevent Market Clearing? An Experimental Investigation,” Quarterly Journal of Economics, 108, pages 437-460.

Fehr, E., and K. Schmidt, (1999). “A Theory of Fairness, Competition and Co-operation,” Quarterly Journal of Economics, 114, pages 817-868.

(2006). "The Economics of Fairness, Reciprocity and Altruism-Experimental Evidence and New Theories," in Kolm, S, and Ythier, J. M. (Eds), Handbook of the Economics of Giving, Altruism and Reciprocity.

Forsythe, R., J. Korowitz, N. Savin, and M. Sefton, (1994). "Fairness in Simple Bargaining Games,” Games and Economic Behavior, 6, pages 347-369.

Gul, F, and W. Pesendorfer, (2006). “The Canonical Type Space for Interdependent Preferecnes,” mimeo, Princeton University.

Güth, W., R. Schmittberger, and B. Schwarze, (1982). “An Experimental Analysis of Ultimatum Bargaining,” Journal of Economic Behavior and Organization, 3, pages 227-247.

Halevy, Y., and M. Peters, (2013). “Other-Regarding Preferences: Outcomes, Intentions or Interdepence?” mimeo, University of British Columbia.

Levine, D., (1998). “Modeling Altruism and Spitefulness in Experiments," Review of Economic Dynamics, 1, pages 593-622. 
Lowe, R., and G. Ritchey, (1973). "Relation of Altruism to Age, Social Class, and Ethnic Identity,” Psychological Reports, 33, pages 567-572.

Milgram, S., L., Mann, and S. Harter, (1965). “The Lost-Letter Technique: A Tool of Social Research,” Public Opinion Quarterly, 29, pages 437-38.

Rabin, M., (1993). “Incorporating Fairness into Game Theory and Economics,” American Economic Review, 83(5), pages 1281-1302.

Rotemberg, J., (2008). “Minimally Acceptable Altruism and the Ultimatum Game,” Journal of Economic Behavior and Organization, 66 (3-4), pages 457-476.

Roth, A., M. Malouf, and J. Murningham, (1981). "Sociological Versus Strategic Factors in Bargaining,” Journal of Economic Behavior and Organization, 2, pages 153177.

Samuelson, P., (1991). “Altruism as a Problem Involving Group Versus Individual Selection in Economics and Biology,” American Economic Review, 83 (2), pages 143-148.

Sen, A., (1995). "Moral Codes and Economic Success,” in Britten, C. S., Hamlin, A. (Eds), Market Capitalism and Moral Values. Edward Eldar, Aldershot.

Simon, H., (1993). “Altruism and Economics,” American Economic Review, 83 (2), page $156-161$.

Smith, A., (1759). The Theory of Moral Sentiments, London: Printed for A. Millar, in the Strand; and A. Kincaid and J. Bell, in Edinburgh. 


\section{Figure 1. Map of Beijing}

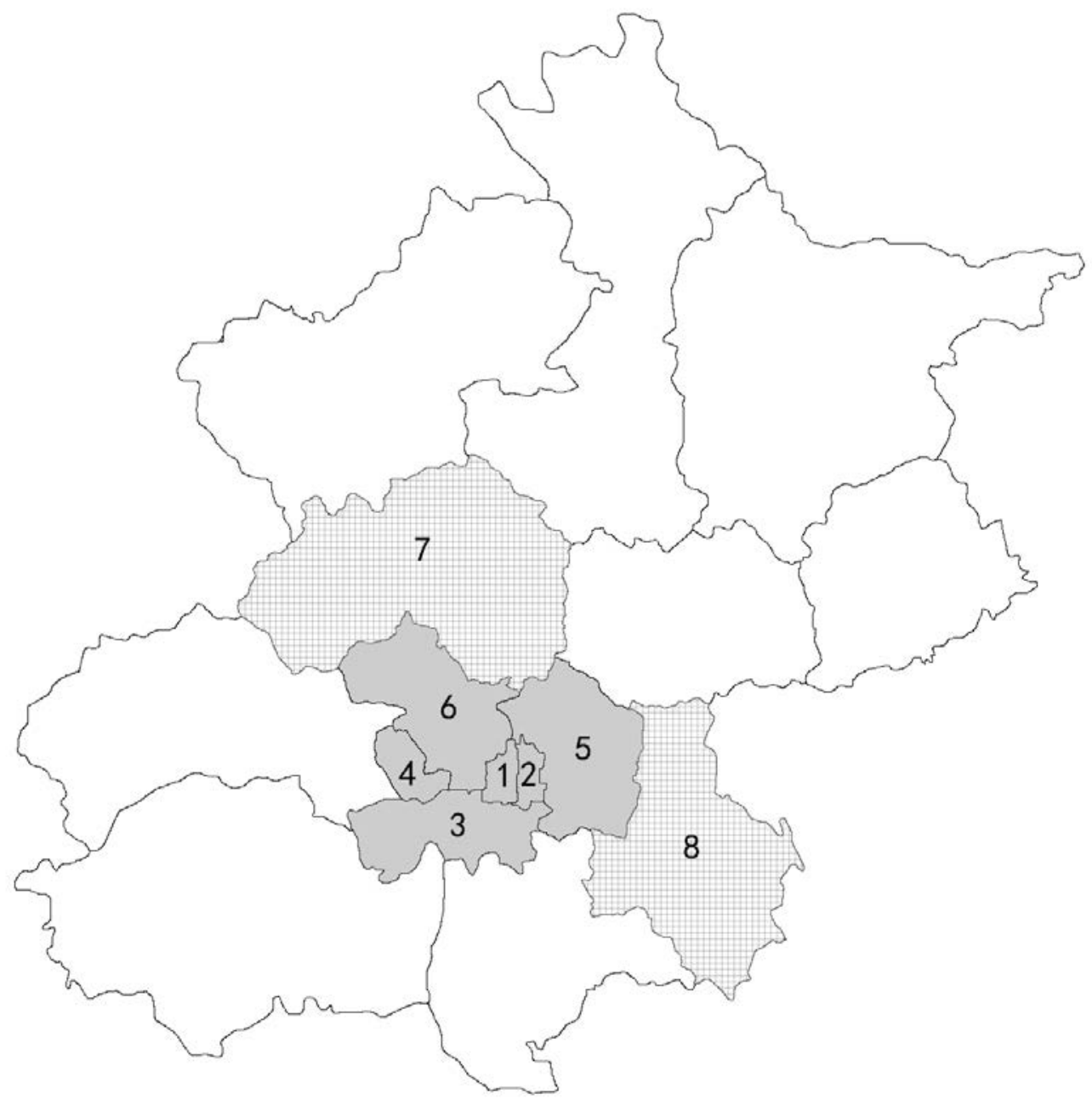

Notes: 1. Xicheng District; 2. Dongcheng District; 3. Fengtai Dstrict; 4. Shijingshan District; 5. Chaoyang District; 6. Haidian District; 7. Changping District; 8. Tongzhou District. District 1-6 are in central Beijing. District 7 and 8 are in the suburban area. 
Figure 2. Return Rate by Subgroups
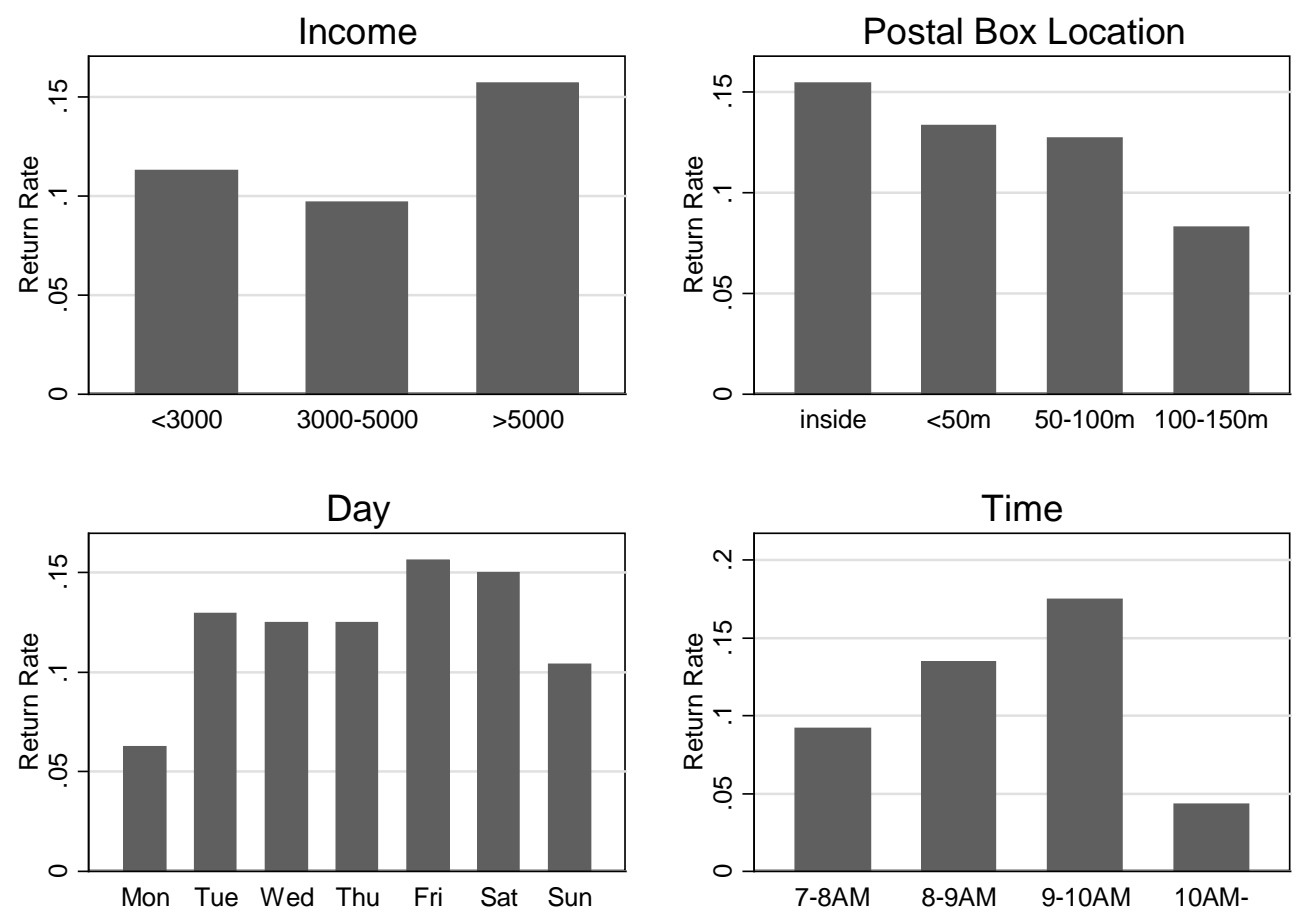
Figure 3. Return Rate by Weather Indicators
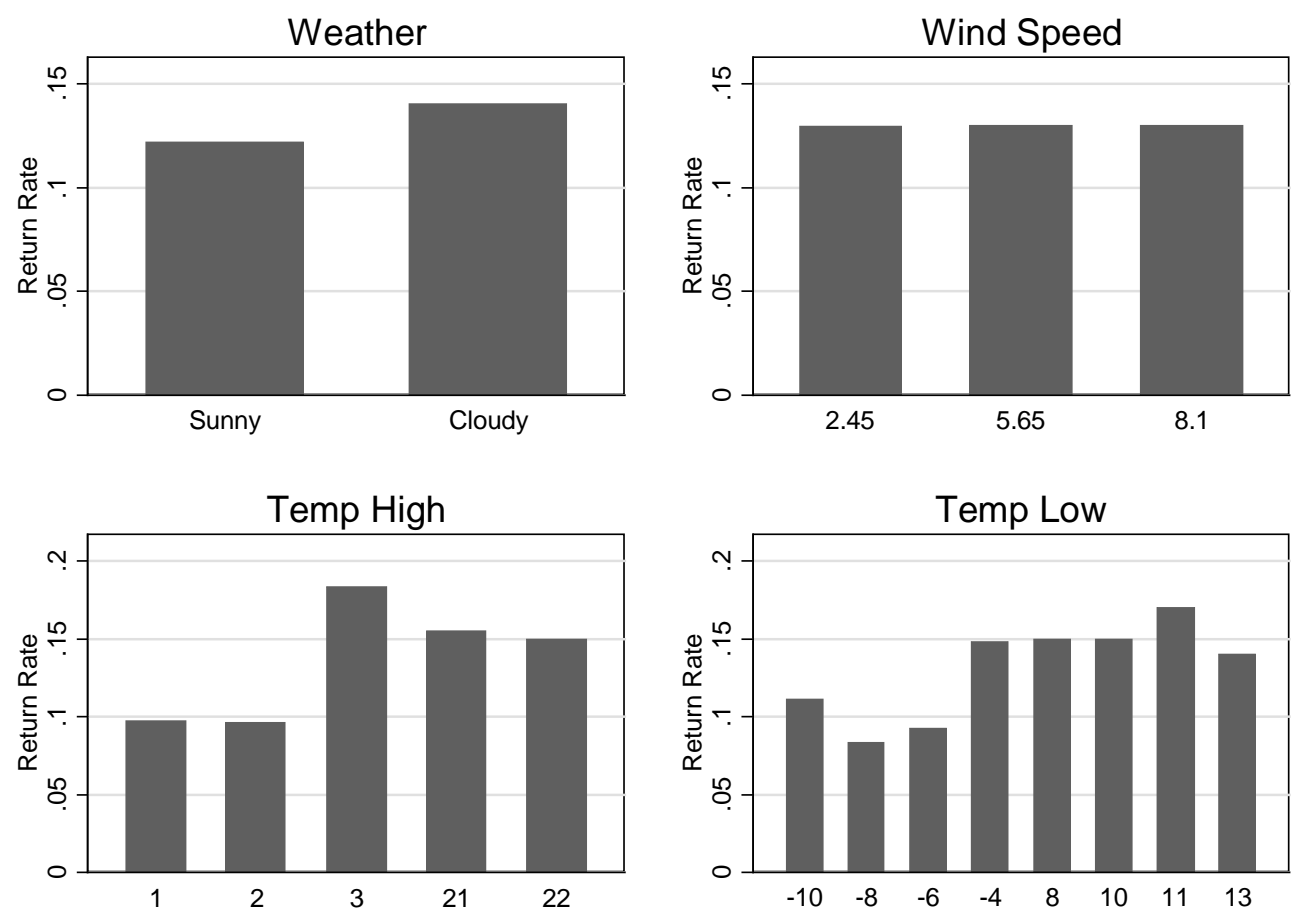
Table 1. Dates, Times and Communities of the Three Experiments

\begin{tabular}{|c|c|c|c|c|}
\hline & $\begin{array}{l}\text { Date } \\
(1)\end{array}$ & $\begin{array}{l}\text { Day } \\
(2)\end{array}$ & $\begin{array}{l}\text { Time } \\
(3)\end{array}$ & $\begin{array}{c}\text { Communities } \\
\text { (4) }\end{array}$ \\
\hline $1^{\text {st }}$ wave & Jan. $1^{\text {st }}, 2012-$ Jan. $4^{\text {th }}, 2012$ & Sun-Wed & 7:05 AM - 13:20 PM & 48 \\
\hline $2^{\text {nd }}$ wave & Nov. $18^{\text {th }}, 2013-$ Nov. $21^{\text {st }}, 2013$ & Tue-Fri & 7:25 AM - 9:06 AM & 60 \\
\hline $3^{\text {rd }}$ wave & Mar. 26 ${ }^{\text {th }}, 2014-$ Mar. $29^{\text {th }}, 2014$ & Wed-Sat & $7: 10$ AM - 9:52 AM & 100 \\
\hline
\end{tabular}


Table 2. Number of Treatment and Control Letters

\begin{tabular}{lccc}
\hline & $\begin{array}{c}\text { Treatment letters } \\
(1)\end{array}$ & $\begin{array}{c}\text { Control letters } \\
(2)\end{array}$ & $\begin{array}{c}\text { Total } \\
(3)\end{array}$ \\
\cline { 2 - 4 } $1^{\text {st }}$ wave & 96 & 96 & 192 \\
$2^{\text {nd }}$ wave & 120 & 120 & 240 \\
$3^{\text {rd }}$ wave & 200 & 200 & 400 \\
Total & 416 & 416 & 832 \\
\hline Notes: a total of two treatment and two control letters was dropped in \\
each community in four consecutive days. The dropping order of the \\
four letters was randomized.
\end{tabular}




\begin{tabular}{|c|c|c|c|c|c|c|c|}
\hline \multicolumn{8}{|c|}{ Table 3. Distribution of Communities by District } \\
\hline District & $\begin{array}{l}\text { Area } \\
(1)\end{array}$ & $\begin{array}{l}\text { First } \\
(2)\end{array}$ & $\begin{array}{l}\text { Second } \\
\text { (3) }\end{array}$ & $\begin{array}{l}\text { Third } \\
\text { (4) }\end{array}$ & $\begin{array}{l}\text { Raw sum } \\
\text { (5) }\end{array}$ & $\begin{array}{c}\text { High Income Communities } \\
\text { (6) }\end{array}$ & $\begin{array}{c}\text { Disposable Income } \\
\text { (7) }\end{array}$ \\
\hline 1.Changping & Suburb & 6 & 0 & 4 & 10 & $10 \%$ & 32,495 \\
\hline 2. Chaoyang & Central & 7 & 15 & 16 & 38 & $47 \%$ & 41,035 \\
\hline 3. Dongchen & Central & 0 & 12 & 0 & 12 & $58 \%$ & 41,676 \\
\hline 4. Fengtai & Central & 0 & 20 & 4 & 24 & $29 \%$ & 37,886 \\
\hline 5. Haidian & Central & 32 & 0 & 64 & 96 & $60 \%$ & 45,953 \\
\hline 6. Shijingshan & Central & 0 & 0 & 4 & 4 & $50 \%$ & 38,657 \\
\hline 7. Tongzhou & Suburb & 3 & 0 & 0 & 3 & $0 \%$ & 33,662 \\
\hline 8. Xicheng & Central & 0 & 13 & 8 & 21 & $57 \%$ & 43,479 \\
\hline Total & & 48 & 60 & 100 & 208 & & \\
\hline \multicolumn{8}{|c|}{$\begin{array}{l}\text { Notes: number of communities in column (2)-(5). Percentage of communities with self-reported average monthly income } \\
\text { above 5,000 RMB in column (6). Annual disposable income per capita for residents with urban Hukou in } 2013 \text { in column } \\
\text { (7). } \\
\text { Sources: annual disposable income per capita for residents with urban Hukou in } 2013 \text { is from the website of the Beijing } \\
\text { City Bureau of Statistics http://www.bjstats.gov.cn/. }\end{array}$} \\
\hline
\end{tabular}




\begin{tabular}{cccccc}
\hline \multicolumn{5}{c}{ Table 4. Weather Indicators } \\
\hline $\begin{array}{c}\text { Wave } \\
(1)\end{array}$ & Date & Temp High & Temp Low & Wind & Weather \\
\hline $1^{\text {st }}$ wave & Jan. 1, 2012 & $(3)$ & $(4)$ & $(5)$ & $(6)$ \\
& Jan. 2, 2012 & 2 & -4 & 2.45 & Cloudy \\
& Jan. 3, 2012 & 1 & -6 & 8.1 & Cloudy \\
& Jan. 4, 2012 & 1 & -8 & 5.65 & Sunny \\
$2^{\text {nd }}$ wave & Nov. 18, 2013 & 3 & -10 & 2.45 & Sunny \\
& Nov. 19, 2013 & 2 & -4 & 2.45 & Cloudy \\
& Nov. 20, 2013 & 1 & -8 & 8.1 & Sunny \\
& Nov. 21, 2013 & 1 & -10 & 5.65 & Sunny \\
$3^{\text {rd }}$ wave & Mar. 26, 2014 & 22 & 10 & 5.65 & Sunny \\
& Mar. 27, 2014 & 21 & 13 & 5.65 & Cloudy \\
& Mar. 28, 2014 & 21 & 11 & 8.1 & Cloudy \\
& Mar. 29, 2014 & 22 & 8 & 5.65 & Sunny \\
\hline Notes: temperatures in degree Celsius. Wind speed in meters per second. \\
\hline \multicolumn{6}{c}{} \\
\hline
\end{tabular}




\begin{tabular}{ccccc}
\hline \multicolumn{5}{c}{ Table 5. Main Experiment Results: Return Rates (\%) } \\
\hline & Overall & Treatment & Control & $\begin{array}{c}\text { Diff } \\
(4)=(2)-(3)\end{array}$ \\
\cline { 2 - 5 } Full sample & $(1)$ & $(2)$ & $(3)$ & Panel A: Full sample \\
& 12.98 & 16.83 & 9.13 & 7.7 \\
& $(832)$ & $(416)$ & $(416)$ & {$[3.31]$} \\
\cline { 2 - 5 } $1^{\text {st }}$ wave & 7.81 & Panel B: Subsample by wave \\
& $(192)$ & $(96)$ & 5.21 & 5.2 \\
$2^{\text {nd }}$ wave & 13.33 & 15 & 11.67 & {$[1.34]$} \\
& $(240)$ & $(120)$ & $(120)$ & {$[0.76]$} \\
$3^{\text {rd }}$ wave & 15.25 & 21 & 9.5 & 11.5 \\
& $(400)$ & $(200)$ & $(200)$ & {$[3.23]$} \\
\hline Notes: observations in parentheses. $t$ statistics for two-tail test in brackets.
\end{tabular}




\begin{tabular}{|c|c|c|c|}
\hline \multicolumn{4}{|c|}{ Table 6. Regression Results } \\
\hline \multirow{3}{*}{ Treatment } & $(1)$ & (2) & (3) \\
\hline & $0.078 * * *$ & $0.078 * * *$ & $0.060 * *$ \\
\hline & $(0.019)$ & $(0.019)$ & $(0.021)$ \\
\hline \multirow{2}{*}{ High income (>5,000 RMB) } & & $0.044^{*}$ & 0.025 \\
\hline & & $(0.021)$ & $(0.018)$ \\
\hline \multirow[t]{2}{*}{ Treatment $\times$ High income } & & & 0.036 \\
\hline & & & $(0.030)$ \\
\hline \multicolumn{4}{|l|}{$\begin{array}{l}\text { Postal box location } \\
\text { (ref=inside) }\end{array}$} \\
\hline \multirow[t]{2}{*}{$<50$ meters } & -0.011 & -0.011 & -0.011 \\
\hline & $(0.019)$ & $(0.018)$ & $(0.018)$ \\
\hline \multirow[t]{2}{*}{ 50-100 meters } & $-0.054 * *$ & $-0.056 * *$ & $-0.056 * *$ \\
\hline & $(0.022)$ & $(0.023)$ & $(0.023)$ \\
\hline \multirow[t]{2}{*}{$100-150$ meters } & -0.079 & -0.071 & -0.071 \\
\hline & $(0.060)$ & $(0.055)$ & $(0.055)$ \\
\hline \multicolumn{4}{|l|}{ Time (ref=7-8AM) } \\
\hline \multirow[t]{2}{*}{$8-9$ AM } & 0.036 & 0.030 & 0.031 \\
\hline & $(0.035)$ & $(0.033)$ & $(0.034)$ \\
\hline \multirow[t]{2}{*}{$9-10 \mathrm{AM}$} & $0.132 * * *$ & $0.127 * * *$ & $0.127 * * *$ \\
\hline & $(0.032)$ & $(0.030)$ & $(0.030)$ \\
\hline \multirow[t]{2}{*}{$10 \mathrm{AM}-$} & 0.049 & 0.043 & 0.042 \\
\hline & $(0.040)$ & $(0.036)$ & $(0.037)$ \\
\hline \multirow[t]{2}{*}{ Weekend } & -0.018 & -0.018 & -0.019 \\
\hline & $(0.017)$ & $(0.016)$ & $(0.017)$ \\
\hline \multirow[t]{2}{*}{ Sunny day } & -0.043 & -0.042 & -0.042 \\
\hline & $(0.044)$ & $(0.045)$ & $(0.045)$ \\
\hline \multirow[t]{2}{*}{ Temp high } & 0.022 & 0.022 & 0.022 \\
\hline & $(0.031)$ & $(0.031)$ & $(0.031)$ \\
\hline \multirow[t]{2}{*}{ Temp low } & -0.006 & -0.006 & -0.006 \\
\hline & $(0.010)$ & $(0.010)$ & $(0.010)$ \\
\hline \multirow[t]{2}{*}{ Wind speed } & -0.005 & -0.005 & -0.005 \\
\hline & $(0.005)$ & $(0.005)$ & $(0.005)$ \\
\hline Observations & 832 & 832 & 832 \\
\hline R-squared & 0.05 & 0.05 & 0.05 \\
\hline \multicolumn{4}{|c|}{$\begin{array}{l}\text { Notes: dependent variable is a dummy variable indicating if a letter was returned. High } \\
\text { income is defined as self-reported community average monthly income above RMB } \\
5,000 \text {. A full set of wave and district dummies is included in both regressions. Robust } \\
\text { standard errors clustered at district in parentheses. }{ }^{* * *},{ }^{* *} \text { and } * \text { indicate significant at } \\
1 \%, 5 \% \text { and } 10 \% \text {. }\end{array}$} \\
\hline
\end{tabular}

